Article

\title{
Traditional Decoction and PUAE Aqueous Extracts of Pomegranate Peels as Potential Low-Cost Anti-Tyrosinase Ingredients
}

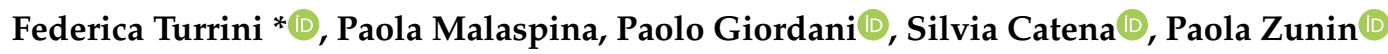 \\ and Raffaella Boggia \\ Department of Pharmacy, University of Genoa, Viale Cembrano 4, 16148 Genoa, Italy; \\ malaspina@difar.unige.it (P.M.); giordani@difar.unige.it (P.G.); catena@difar.unige.it (S.C.); \\ zunin@difar.unige.it (P.Z.); boggia@difar.unige.it (R.B.) \\ * Correspondence: turrini@difar.unige.it
}

Received: 21 March 2020; Accepted: 14 April 2020; Published: 17 April 2020

check for updates

Featured Application: The recycling of the external peels of pomegranate represents an important goal for pomegranate juice manufacturers, since their disposal is expensive and not eco-friendly. Traditional decoction and an innovative ultrasound-assisted method of extraction of pomegranate peels using just water have both led to obtaining aqueous extracts rich in polyphenolic compounds and endowed with anti-tyrosinase activity. Although these aqueous extracts may require a further formulation step for preservation, these findings suggest the possibility of using them as low-cost lightening and/or anti-browning agents, even extemporarily.

\begin{abstract}
The aim of the study is to evaluate the anti-tyrosinase activity of different aqueous extracts obtained from pomegranate juice processing by-products. External pomegranate peels of two certified cultivars (Akko and Wonderful), were extracted using only water as the extraction solvent. A traditional decoction and a pulsed ultrasound-assisted extraction (PUAE), both 10 min long, were performed and compared. All the aqueous extracts proved to be rich in bioactive compounds. In particular, the total phenolic content (TPC) ranged from 148 to $237 \mathrm{mg}$ gallic acid equivalent (GAE)/g of dried peels (DW), the radical-scavenging ability (RSA) ranged from 307 to $472 \mathrm{mg}$ ascorbic acid equivalent (AAE)/g DW, the free ellagic acid content (EA) ranged from 49 to $94 \mu \mathrm{g} / \mathrm{mL}$, and the ellagitannins (ETs) ranged from 242 to $340 \mu \mathrm{g} / \mathrm{mL}$. For both cultivars, PUAE extracts had higher ET content and a lower EC50, while the decoctions had slightly higher TPC, RSA, and free EA amounts. Principal component analysis (PCA) highlighted the direct correlation between the ET content and the tyrosinase enzyme inhibition (lower values of EC50). These findings suggest the potential use of both these natural extracts as low-cost lightening and/or anti-browning ingredients exploitable in several formulations (e.g., cosmetics) or extemporarily usable.
\end{abstract}

Keywords: pomegranate peels; anti-tyrosinase activity; waste recovery; green extraction

\section{Introduction}

Pomegranate (Punica granatum L.) is one of the oldest edible fruits. Mentioned in the Bible, the Koran and Egyptian texts, the first pomegranate crops date back to 3000-4000 BC. [1].

Native to the Middle East and North Africa, today pomegranate is spread globally due to its high longevity, drought and salinity resistance, and adaptability to different climatic conditions [2]. In particular, pomegranate is widely cultivated in Iran, India, China, USA, several countries of the former USSR, South Africa, and in Mediterranean countries such as Spain, Turkey, Egypt, Israel, 
Morocco and Tunisia [3]. In Italy, this resilient and rustic crop recently has shown a growing diffusion, especially in central and southern areas, in response to increasing market demand for pomegranate and, at the same time, with the aim of valorizing marginal land facing climatic change.

Pomegranate juice is the main industrial product obtained from this fruit. In addition to direct consumption, fresh arils (marketed as ready-to-eat products) and pomegranate seed oil have also recently gained an important industrial relevance [3].

One drawback in pomegranate juice industrial production is the large amount of waste, since juice represents about only $30 \%$ of the pomegranate fruit fresh weight. External peels are the most abundant by-products (about 50\% of the total fruit weight) [4,5]. Even if they represent an expensive disposal problem, they are at the same time a promising source of phenolic compounds for exploitation. Ellagic acid (EA), in its free form or in the form of ellagitannins (ETs), is considered the main phenolic compound responsible for the numerous health properties of pomegranate, and is mainly concentrated in the peels with respect to the juice [6,7]. The functional properties of EA are largely reported in the literature $[8,9]$. Among the described healthy properties of pomegranate peel extracts, a previous study indicated that its methanolic peel extracts also inhibit tyrosinase activity $[10,11]$.

The tyrosinase metallo-enzyme, widely distributed in nature, is fundamental in melanogenesis and enzymatic browning. It can be reversibly or irreversibly inhibited by several molecules that block the melanogenesis process in animals, as well as causing the undesired browning in fruits and vegetables [12]. Anti-tyrosinase compounds can be useful both as lightening and anti-browning ingredients in several commodities, such as cosmetics, pharmaceutics, and agri-food products. The color of skin, as well as hair and eyes, is determined by the melanin pigment [13]. In human beings, physiological changes in the normal production of melanin may lead to the appearance of freckles, skin spots or, in the worst case, to the development of melanomas [14-16]. Melanin is synthesized starting from a series of reactions controlled mainly by the activity of the tyrosinase enzyme, a monophenol monooxygenase capable of enclosing a single oxygen atom in the phenolic substrate, oxidizing it to $o$-diphenol and then transforming it into o-quinone $[17,18]$.

EA is a cosmetic ingredient classified as a skin conditioner (CAS number: 476-66-4) [19]. In particular, it is considered an anti-aging, antiwrinkle, antimicrobial, antioxidant, astringent, moisturizing, and lightening/whitening agent [20]. Several authors have described the action of EA on skin pigmentation [21,22]. EA inhibits tyrosinase activity by chelation of the copper atoms present in the active site of the enzyme itself and, for this reason, it has been approved as a lightening ingredient in cosmetic formulations [21]. Nevertheless, there is a large interest in finding low-cost natural extracts with efficiency and safety features as recently reported by Zolghadri et al. [12].

In previous papers, the authors described different extraction strategies to valorize both the external peels (major waste) and the squeezing marcs (internal by-products), exploiting the cavitation of ultrasound extraction in order to increase the mass transfer rate between the peels and the extraction solvent in order to enhance the bioactive compounds recovery useful for a nutraceutical use [4,23].

In this paper, a simple, rapid, and low-cost strategy in the form of traditional decoction and the more innovative pulsed ultrasound-assisted extraction (PUAE) of oven-dried pomegranate peels were applied for the same time period, with the aim to obtain potential low-cost anti-tyrosinase ingredients from these by-products. Water, which is a basic element of both a greener and safer chemistry approach compared to methanol or other organic solvents [24,25], was employed alone as the extraction solvent. PUAE is an example of 'green' extraction technology, widely used for the extraction of food and natural products, and able to considerably reduce the extraction times and increase the extraction yield maintaining high reproducibility [26].

Akko and Wonderful, corresponding to an early and a late pomegranate variety, respectively, are some of the most wide-spread commercial pomegranate cultivars, in virtue of their soft seeds and welcome organoleptic features [4]. Wonderful is the most cultivated commercial cultivar in the Mediterranean region. However, the Akko cultivar, due to its early availability, has recently been introduced in these areas to ensure a continuous offer for the market [27]. 
To the best of our knowledge, no studies of the aqueous extracts of the Akko and Wonderful varieties of pomegranate as sources of anti-tyrosinase compounds have been conducted, and this is the object of our investigation.

\section{Materials and Methods}

\subsection{Pomegranate Samples}

Pomegranate fruits of Akko and Wonderful certified cultivars were harvested at Masseria FruttiRossi (https://lomesuperfruit.com/it/home) in Castellaneta Taranto (Italy), which includes 250 hectares of crops and represents the major Italian pomegranate producer.

Fruits were collected at full maturity (Maturity Index, MI $=14.5 \pm 2.5$ ), during September and November 2018, respectively, for Akko and Wonderful cultivars, and immediately processed to obtain the corresponding juice. Peels, manually separated during the juice processing, were dried using a traditional heating oven (Binder FED53, Goettingen, Germany) for $48 \mathrm{~h}$ at $40{ }^{\circ} \mathrm{C}$. Before the extraction process, dried peels were finely ground by a Grindomi $\times 200 \mathrm{M}$ (Retsch, Haan, Germany) for $20 \mathrm{~s}$ at $5000 \mathrm{rpm}$ and finally sieved by a $150 \mu \mathrm{m}$ sieve to obtain a fine and homogeneous material.

\subsection{Standards and Reagents}

All standards and reagents used were analytical grade. DPPH (1,1-diphenyl-2-picrylhydrazyl) and Folin-Ciocalteu reagents, gallic acid, ascorbic acid, ellagic acid, cyanidine-3-O-glucoside chloride, and methanol were supplied by SIGMA (Steinheim, Germany). Ethanol, acetic acid, hydrochloric acid, and sodium hydroxide were purchased from VWR Chemical (Radnor, PA, USA). L-tyrosine, kojic acid, and mushroom tyrosinase for tyrosinase inhibition assay were supplied by SIGMA (Steinheim, Germany). High purity water (HPW) produced with a Millipore Milli-Q system (Millipore, Bedford, MA, USA) was used throughout. All solvents used for chromatographic purposes were HPLC grade.

\subsection{Pomegranate Peel Extraction}

Peel extraction, both by traditional decoction and by 'green' extraction exploiting the ultrasound action, was performed. Only water was used as the extraction solvent under both methods. The same extraction time $(10 \mathrm{~min})$ and the same solvent/solid ratio (40/1, considering the dried peel weight) were used for both extraction processes. Each extraction was performed in duplicate and all the obtained extracts were analytically analyzed.

\subsubsection{Traditional Decoction (D)}

The decoction of pomegranate peels was carried out by adding the milled dried materials to $40 \mathrm{~mL}$ of Milli-Q water in a beaker. This suspension was heated and kept boiling for $10 \mathrm{~min}$. Then, it was filtered by Buchner, using Whatman $\mathrm{n}$. 1 paper, and centrifuged at relative centrifugation force (RCF or G-force) equal to 2016 for $10 \mathrm{~min}$. The final extracts (AK_D and WO_D) were kept at $-20^{\circ} \mathrm{C}$ until further analysis.

\subsubsection{Green Extraction: Pulsed Ultrasound-Assisted Extraction (PUAE)}

Ultrasonication was applied directly by an Hielscher UP200St (Teltow, Germany) in pulsed modality (PUAE). Maximum nominal output power of 200W, frequency of $26 \mathrm{kHz}$, and a titanium probe $(7 \mathrm{~mm}$ diameter) were employed for the sonication. The pulse duration and pulse interval refer to "on" time and "off" time of the sonicator. The pulse duration/pulse interval ratio was 4/1 (duty cycle $80 \%$ ). The amplitude level was set to $50 \%$. During the extraction process, temperature was controlled to be below $65^{\circ} \mathrm{C}$ (temperature variation during the extraction period was lower than $40^{\circ} \mathrm{C}$ ). The obtained extracts (AK_PUAE and WO_PUAE), similarly to the decoction described in the previous paragraph, were filtered, centrifuged and stored frozen until analysis. 


\subsection{Characterization of the Peel Aqueous Extracts}

$\mathrm{pH}$ was evaluated by electrochemical measurements using a pHmeter (Jenway 3510, Stone, UK). The total soluble content (TSS), expressed in ${ }^{\circ}$ Brix, was determined at $20{ }^{\circ} \mathrm{C}$ by a digital refractometer (Hanna Instruments, Milano, Italy) (Table 1). The total polyphenol content (TPC) and the Radical Scavenging Activity (RAS) of all the aqueous peel extracts (D and PUAE) were determined spectrophotometrically. The total anthocyanin content (TAC) and the EA and ET amounts were quantified by chromatography.

Table 1. $\mathrm{pH}$, TSS, and TAC values of Akko and Wonderful pomegranate peel aqueous extracts obtained by the traditional (D) and innovative extraction technique (PUAE). Results are reported as mean \pm SE.

\begin{tabular}{|c|c|c|c|c|c|}
\hline & Cultivar & $\begin{array}{l}\text { Extraction } \\
\text { Method }\end{array}$ & $\mathrm{pH}$ & TSS $\left({ }^{\circ}\right.$ Brix $)$ & $\begin{array}{c}\text { TAC (mg } \\
\text { Cyanidin-3-O-Glucoside/ } \\
\text { g DW) }\end{array}$ \\
\hline AK_D & Akko & Decoction & $3.92 \pm 0.04$ & $3.10 \pm 0.10$ & $0.14 \pm 0.01$ \\
\hline AK_PUAE & Akko & PUAE & $4.04 \pm 0.03$ & $1.95 \pm 0.05$ & $0.06 \pm 0$ \\
\hline WO_D & Wonderful & Decoction & $3.56 \pm 0.02$ & $2.05 \pm 0.05$ & $0.08 \pm 0$ \\
\hline WO_PUAE & Wonderful & PUAE & $3.65 \pm 0.03$ & $1.80 \pm 0$ & $0.05 \pm 0.02$ \\
\hline
\end{tabular}

\subsubsection{Determination of Total Polyphenols}

TPC was determined by an UV-Vis Agilent 8453 spectrometer (Waldbronn, Germany) following the Folin-Ciocalteu method previously reported by Singleton et al. [28]. TPC was determined in the peel aqueous extracts as milligrams of gallic acid equivalent in $100 \mathrm{~mL}$ of extract (mg GAE/100 mL) using an appropriate gallic acid calibration curve $\left(R^{2}=0.9887\right)$ as the reference standard. Then, the results were transformed in $\mathrm{mg}$ GAE/g of pomegranate peel dry weight (DW). Each sample was analyzed in duplicate and the results were reported as mean values \pm standard error (SE).

\subsubsection{Determination of the Radical Scavenging Activity}

RSA of the achieved extracts was spectrophotometrically determined by DPPH• (1,1-diphenyl2-picryl-hydrazyl) in vitro assay [29]. This method, widely used for food matrices, allowed the detection of the antiradical activity colorimetrically based on the discoloration of the stable colored $\mathrm{DPPH} \bullet$ recorded at $515 \mathrm{~nm}$. Ascorbic acid was used as the reference standard and the recorded absorbances of the extracts were compared with the absorbance of solutions of ascorbic acid (AA) at known concentration $\left(y=0.5824 x-0.0036 ; R^{2}=0.9975\right.$; range of linearity $0.1-1 \mathrm{mM}$ ). The antiradical activity was obtained as $\mathrm{mg}$ ascorbic acid equivalent in $100 \mathrm{~mL}$ of extract (mg AAE/100 mL) and then converted as mg AAE/g of pomegranate peel DW. Two replicated determinations were performed for each sample and data were reported as mean values $\pm \mathrm{SE}$.

\subsection{HPLC Analysis}

\subsubsection{Determination of EA and ETs}

The HPLC determination of EA and ETs was realized using an Agilent 1100 LC-DAD (Agilent Technologies, Palo Alto, USA) [4]. A C-18 Kromasil 100 ${ }^{\circledR}$ (Akzo-Nobel, Amsterdam, NL) column $(250 \times 4 \mathrm{~mm}, 5 \mu \mathrm{m})$, thermostat-controlled at $30^{\circ} \mathrm{C}$, was used for the chromatographic separations. Gradient elution of acetic acid/methanol/water (2:400:598) (solvent A) and methanol (solvent B), with a $1 \mathrm{~mL} / \mathrm{min}$ flow rate was employed as follows: $100 \% \mathrm{~A}$ at $0 \mathrm{~min}, 0 \% \mathrm{~A}$ at $20 \mathrm{~min}, 100 \% \mathrm{~A}$ reset in $10 \mathrm{~min}$ and held for $5 \mathrm{~min}$. The injection volume was $10 \mu \mathrm{L}$, and the detection wavelengths were set between 220 and $600 \mathrm{~nm}$. Free EA in the extracts was quantified at $245 \mathrm{~nm}$ by external standard, using an appropriate 4-point calibration line $\left(y=251.58 x-204.41 ; R^{2}>0.999\right.$; range of linearity $2.5-200 \mu \mathrm{g} / \mathrm{mL}$; $\mathrm{LOD}=0.78 \mu \mathrm{g} / \mathrm{mL} ; \mathrm{LOQ}=2.36 \mu \mathrm{g} / \mathrm{mL}$ ). The total ET content was determined after the preliminary acid hydrolysis (performed in replicate) of extracts in order to hydrolyze ETs in EA [4,30]. A quantity of 
$2 \mathrm{~mL}$ of each extract, added to $2 \mathrm{~mL} \mathrm{HCl} 2 \mathrm{M}$, was heated at $100^{\circ} \mathrm{C}$ for $1 \mathrm{~h}$ in a boiling water bath. After the cooling time, $1 \mathrm{~mL}$ of $\mathrm{NaOH} 2 \mathrm{M}$ and $6 \mathrm{~mL}$ of methanol were added. The final solution was vortexed and filtered before the injection. Two replicated determinations of EA and ETs were performed for each sample analyzed and data were reported as mean values \pm SE. The EA chromatogram of one pomegranate peel aqueous extract is reported in the Supplementary Materials Figure S1.

\subsubsection{Determination of Total Anthocyanins}

TAC identification and quantification was conducted using an HPLC-DAD method [31]. Analysis were carried out on a C-18 core-shell column (Agilent Poroshell $120 \mathrm{EC}, 3 \mathrm{~mm} \times 150 \mathrm{~mm}, 2.7 \mu \mathrm{m}$ particle size) thermostat-controlled at $30^{\circ} \mathrm{C}$. Gradient elution of water acidified at $\mathrm{pH} 2.14$ by formic acid (solvent A) and acetonitrile (solvent B), with a $0.4 \mathrm{~mL} / \mathrm{min}$ flow rate, was employed as follows: $95 \%$ A at $0 \mathrm{~min}$, $70 \% \mathrm{~A}$ at $25 \mathrm{~min}, 45 \% \mathrm{~A}$ at $35 \mathrm{~min}$, and $0 \% \mathrm{~A}$ at $42 \mathrm{~min}$, held for $3 \mathrm{~min}$. Anthocyanins were quantified at $515 \mathrm{~nm}$ by external standard, using an appropriate 4-point cyanidin-3-O-glucoside calibration line (y $=71.52 \mathrm{x}-12.54 ; \mathrm{R}^{2}>0.999 ;$ range of linearity $\left.1.5-150 \mu \mathrm{g} / \mathrm{mL} ; \mathrm{LOD}=0.39 \mu \mathrm{g} / \mathrm{mL} ; \mathrm{LOQ}=1.17 \mu \mathrm{g} / \mathrm{mL}\right)$. Each sample was analyzed in duplicate and the results, expressed as $\mu$ g cyanidin-3-O-glucoside/g DW, were reported as mean values $\pm \mathrm{SE}$. The anthocyanin profile of one pomegranate peel aqueous extract is reported in the Supplementary Materials Figure S2.

\subsection{Tyrosinase Inhibition Property}

A $25 \mathrm{mg} / \mathrm{mL}$ stock solution of each cultivar and treatment, prepared as described in the previous paragraph, was diluted in water to obtain a series of test solutions with final concentrations of 10, 50, $100,250,350$, and $500 \mu \mathrm{g} / \mathrm{mL}$. Components of the reaction mix were added to each well of 96-well plates in the following order: $70 \mu \mathrm{L}$ of phosphate buffer, $60 \mu \mathrm{L}$ of extract solutions (water for controls), $10 \mu \mathrm{L}$ of mushroom tyrosinase (Sigma-Aldrich, T3824, $25 \mathrm{kU}, 125 \mathrm{U} / \mathrm{mL}$ in phosphate buffer, $\mathrm{pH}$ 6.8), and $70 \mu \mathrm{L}$ L-tyrosine $(0.3 \mathrm{mg} / \mathrm{mL}$ in water). Kojic acid was used instead of pomegranate solutions as a positive control. Blank samples without enzyme were also included for all conditions. Plates were then incubated at $30^{\circ} \mathrm{C}$ for $60 \mathrm{~min}$, and absorbance was read at $505 \mathrm{~nm}$ in a microplate reader (Spectra Max 340PC). Percent inhibitory activity (I\%) was calculated according to the formula:

$$
\mathrm{I} \%=\left[1-\frac{\left(\mathrm{A}_{\mathrm{ex} / \mathrm{en}}-\mathrm{A}_{\mathrm{ex}}\right)}{\left(\mathrm{A}_{\mathrm{en}}-\mathrm{A}_{\mathrm{bk}}\right)}\right] \times 100
$$

where Aex/en = absorbance of sample mixture with extract and enzyme; Aex = absorbance of sample mixture with extract and without enzyme; Aen = absorbance of sample mixture with enzyme and without extract; $\mathrm{Abk}=$ absorbance of sample mixture without enzyme and extract (blank).

\subsection{Statistical Analysis}

All the measurements performed were replicated and the results are expressed as mean value \pm SE. Analysis of variance (ANOVA) was performed using the Excel Data Analysis Tool (Microsoft Corporation, Seattle, WA, USA). A $p$-value lower than 0.05 was statistically significant. Principal component analysis (PCA), based on the NIPALS algorithm [32], was performed by CAT (Chemometric Agile Tool) [33]. This chemometric software, based on R, was developed by the Chemistry Group of the Italian Chemical Society.

\section{Results and Discussion}

It is known that bioactive compounds are variable in pomegranate, and generally in plant material, according to genetic factors, different collection stages, pedoclimatic conditions of the sampling sites (growing wild or cultivation), application of agricultural practices, and post-harvest handling [34,35].

For this investigation, pomegranates of Akko and Wonderful cultivars were grown in the same cultivation area in Southern Italy, under the same pedoclimatic conditions, and using the same 
agro-techniques. These samples, coming from one of the biggest Italian producers, are representative of the commercial cultivars most widespread and marketed in Italy. Fruits were harvested in different collection periods according to the cultivar maturity but at the same maturity status.

$\mathrm{pH}, \mathrm{TSS}$, and TAC of both the aqueous extracts (D and PUAE) of Akko and Wonderful cultivar are reported in Table 1.

One-way ANOVA, analyzing the mean differences of the $\mathrm{pH}$ values, showed significant differences $(p<0.05)$ between the cultivars (Akko and Wonderful), but no significant differences are highlighted between the two different extraction methods (D and PUAE) for the same cultivar (Table 2).

Table 2. One-way ANOVA results.

\begin{tabular}{cccccc}
\hline \multirow{2}{*}{ Variable } & ANOVA Data & AK_D/AK_PUAE & WO_D/WO_PUAE & $\begin{array}{c}\text { AK_D/ } \\
\text { WO_D }\end{array}$ & $\begin{array}{c}\text { AK_PUAE/ } \\
\text { WO_PUAE }\end{array}$ \\
\hline \multirow{2}{*}{$\mathrm{pH}$} & $\mathrm{F}$ & 7.353 & 8.022 & 89.379 & 84.5 \\
& $p$ value & 0.113 & 0.105 & 0.011 & 0.012 \\
$\mathrm{TSS}$ & $\mathrm{F}$ & 105.8 & 25 & 88.2 & 9 \\
& $p$ value & 0.009 & 0.038 & 0.011 & 0.095 \\
$\mathrm{RSA}$ & $\mathrm{F}$ & 3.038 & 17.838 & 12.012 & 9.064 \\
& $p$ value & 0.223 & 0.052 & 0.074 & 0.095 \\
$\mathrm{TPC}$ & $\mathrm{F}$ & 51.789 & 5.184 & 43.586 & 0.798 \\
& $p$ value & 0.019 & 0.151 & 0.022 & 0.466 \\
TAC & $\mathrm{F}$ & 64 & 5.444 & 36 & 1 \\
& $p$ value & 0.015 & 0.145 & 0.027 & 0.423 \\
EA & $\mathrm{F}$ & 17.323 & 5.758 & 57.772 & 9.221 \\
& $p$ value & 0.053 & 0.138 & 0.017 & 0.093 \\
ETS & $\mathrm{F}$ & 3.959 & 9.755 & 0.542 & 0.236 \\
& $p$ value & 0.185 & 0.089 & 0.538 & 0.675 \\
\hline
\end{tabular}

As regards TSS, one-way ANOVA highlighted significant differences $(p<0.05)$ between D and PUAE extracts for both the cultivars. In particular, D extracts (AK_D and WO_D) showed higher TSS with respect to the corresponding PUAE extracts (AK_PUAE and WO_PUAE). This is likely because the higher boiling temperature of decoction compared to sonication allowed the partial hydrolysis of glucosides and the release of sugar moieties [36]. No significant difference between AK_PUAE and WO_PUAE was observed, probably because the extraction temperature was similarly maintained under control $\left(<65^{\circ} \mathrm{C}\right)$. According to previous studies [37], extraction temperature in the range of $60-70{ }^{\circ} \mathrm{C}$ was optimal for the UAE of EA from pomegranate peels.

For both the extraction methods the obtained extracts can be considered almost sugar-free if compared with the corresponding pomegranate juice (Akko: TSS $=15.20 \pm 0.42$; Wonderful: TSS $=$ $17.01 \pm 0.57)$, as previously studied by the authors [23].

Previous studies have shown that cultivar, maturity stage, and environmental factors could significantly influence the TAC of pomegranate peel extracts [5,38,39]. Cyanidin and pelargonidin derivatives are the most abundant anthocyanin pigments isolated from the peels. In particular, cyanidin 3-O-glucoside was considered one of the major anthocyanins detected in these by-products [38]. In all the extracts the TAC was slightly lower compared to those reported in literature for other pomegranate cultivars [40] even if the cited authors used methanol as an extraction solvent. One-way ANOVA, analyzing the mean differences of the TAC, showed significant differences $(p<0.05)$ between the cultivars when extracts were obtained by decoction. On the contrary, no significant differences between AK_PUAE and WO_PUAE were observed. Different results were shown for the two cultivars by comparing the two extraction methods (D and PUAE).

Figure 1 reports the TPC and the RSA results of the peel aqueous extracts (D and PUAE) belonging to the two cultivars investigated. 


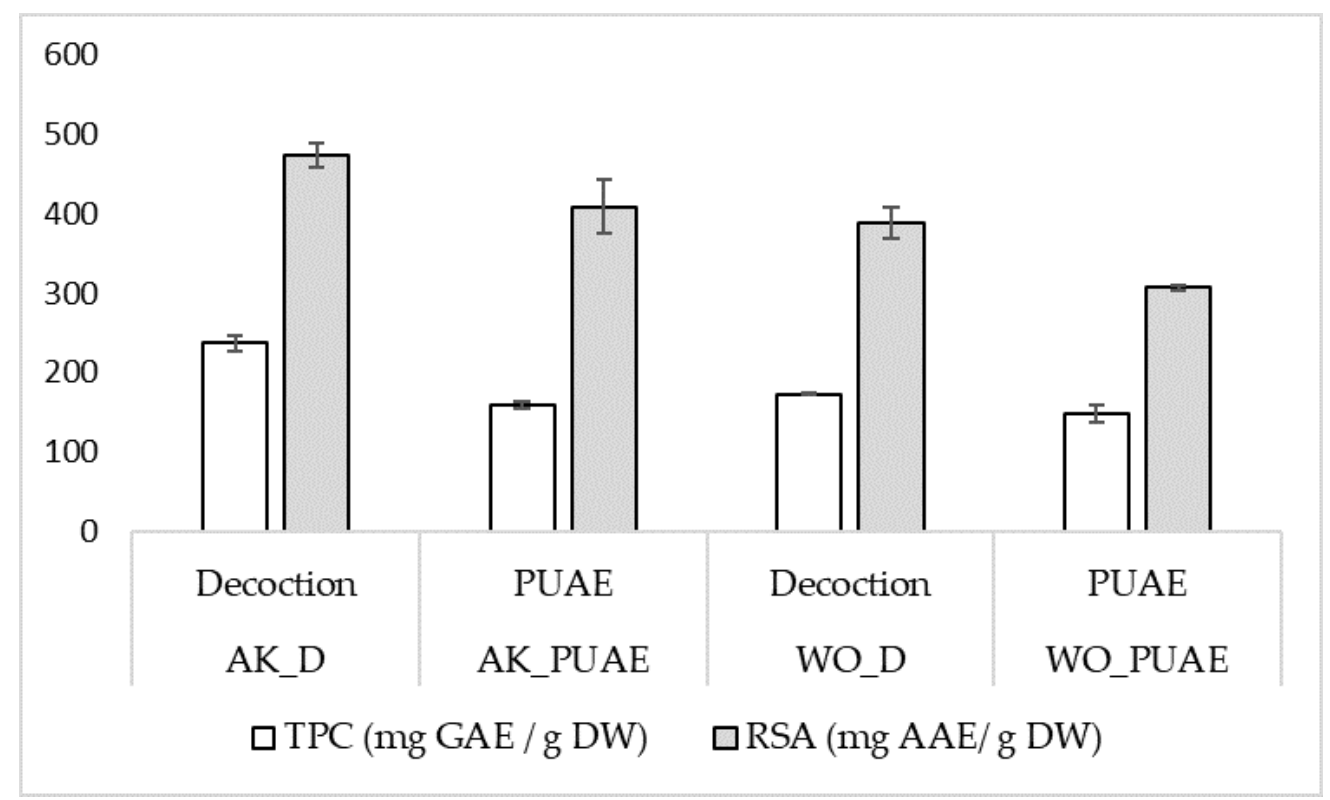

Figure 1. TPC and RSA of Akko and Wonderful pomegranate peel aqueous extracts obtained by the traditional (D) and innovative extraction technique (PUAE). Bars show mean values and SE of the replicated data.

TPC and RSA values were moderately correlated $\left(R^{2}=0.7304\right)$. The decoction demonstrated higher TPC compared to the extract obtained by sonication (PUAE) in both cultivars. In fact, one-way ANOVA, analyzing the mean differences of the TPCs, showed significant differences $(p<0.05)$ between the extraction methods (D and PUAE) for both cultivars. Analyzing the two different cultivars, there is a significant difference between AK_D and W_D, with a higher value for Akko. On the contrary, no significant differences in TPC were observed between the cultivars when the extraction was performed by PUAE.

As regards RSA, no significant differences were observed by ANOVA in Akko and Wonderful cultivars extracted both by decoction and PUAE, although the statistical significance was very low (Table 2).

Some previous studies, which considered aqueous extracts of pomegranate peels starting from different cultivars, showed an extraction efficiency, expressed as TPC, lower than that obtained in the present work; for example, El-Said et al. 2014 [41] reported a TPC equal to $16.343 \mathrm{mg} \mathrm{GAE} / \mathrm{g}$ for aqueous extracts obtained from similarly oven-dried peels, which is more than 10 times less than those reported in Figure 1. Rahja et al. 2019 [24] described different 'green' extraction methods using just water as a solvent to efficiently extract the bioactive fraction of pomegranate peels. From a comparison of different aqueous extraction methods applied to pomegranate peels, such as ultrasound (UAE), infrared, pulsed electric fields, and high-voltage electrical discharges (HVED), HVED-assisted extraction, applied for $7 \mathrm{~min}$., yielded a maximal concentration of phenolics equal to $46 \mathrm{mg} \mathrm{GAE} / \mathrm{g}$ DW. After the same period, the UAE method yielded phenolic recovery equal to $14.5 \mathrm{mg}$ of GAE/g DW, which is approximately 10-16 times lower than the TPCs of those reported in Figure 1. Recently, Kaderides et al. 2019 [42], exploiting the action of ultrasound and microwave to extract the phenolic compounds from pomegranate peels, described TPCs equal to $119.82 \mathrm{mg}$ GAE/g dry peel and $199.4 \mathrm{mg}$ GAE/g dry peel, respectively, which are more in accordance with the values described in this study (148-237 mg GAE/g DW).

Figure 2 reports the free EA and ET amounts of the peel aqueous extracts (D and PUAE) belonging to the two different cultivars investigated. 


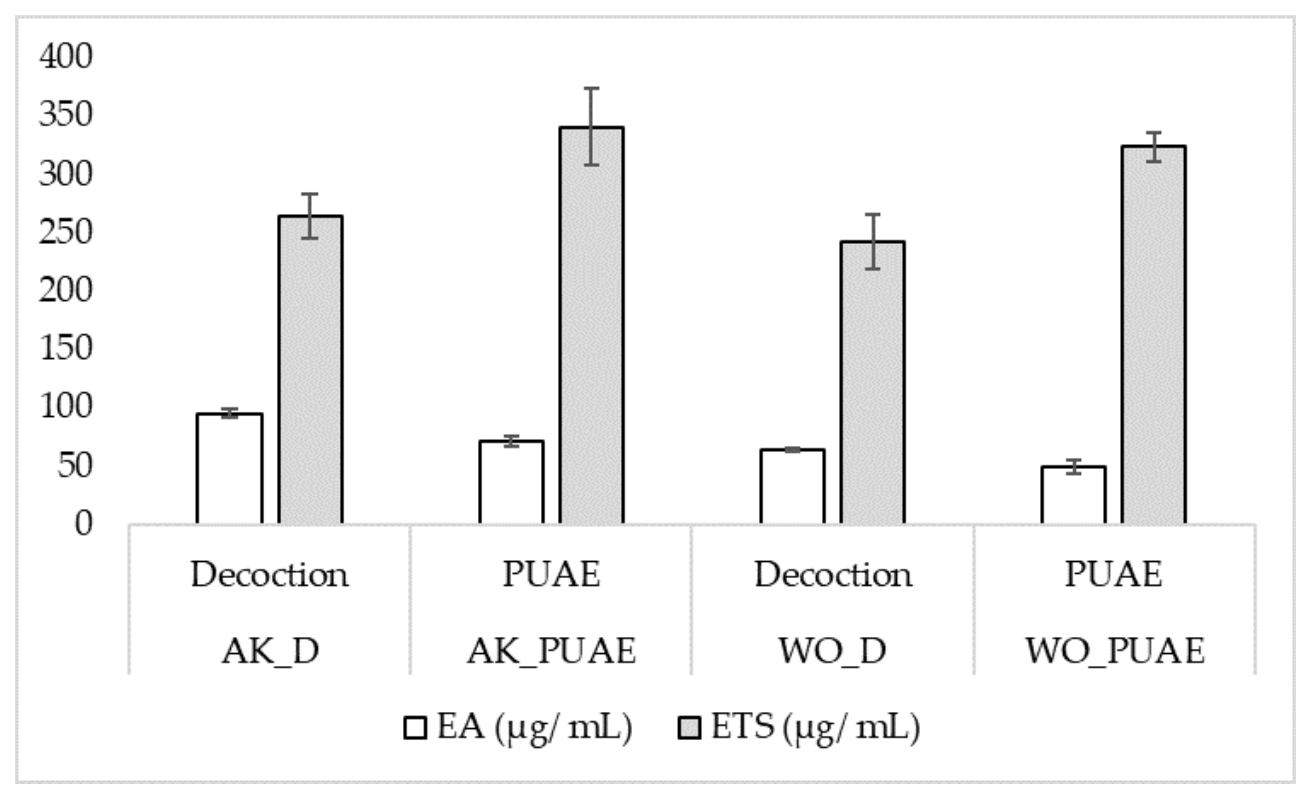

Figure 2. EA and ET amounts of Akko and Wonderful pomegranate peel aqueous extracts obtained by the traditional (D) and innovative extraction technique (PUAE). Bars show mean values and SE of the replicated data.

Free EA and ET contents were not correlated. In particular, for both cultivars, the decoction (AK_D and WO_D) showed higher EA and lower ET contents compared to the PUAE extracts (AK_PUAE and WO_PUAE). The PUAE extract, according to several other green strategies reported in the literature [42-44], confirms its superiority in terms of ET recovery, even if the simplest decoction is endowed with a higher free EA content, probably due to the highest boiling temperature, which allows the partial hydrolysis of ETs with the consequent release of the common aglycone (EA) and some sugar moieties [36]. The aim of this investigation was the comparison between the innovative PUAE and the traditional decoction. For this reason, the same experimental conditions (extraction time, liquid/solid ratio, extraction solvent) were maintained for both of the extraction strategies with the exception of the temperature, which was the only variable that changed (PUAE $<65^{\circ} \mathrm{C}$ and $\mathrm{D}=100^{\circ} \mathrm{C}$ ). ETs are stable in acidic conditions ( $\mathrm{pH}=2-4)$, which is their natural condition; nevertheless, they rapidly degrade in neutral and mildly basic media, especially at higher temperatures [36]. In acidic conditions, as in the pomegranate extracts, ETs show high stability in the range of temperature $20-60{ }^{\circ} \mathrm{C}$ but at $80^{\circ} \mathrm{C}$ they gradually degrade [36].

One-way ANOVA, analyzing the mean differences of the free EA content, showed significant differences $(p<0.05)$ only between AK_D and WO_D. On the contrary, as regards the mean differences of the ET content, one-way ANOVA did not reveal significant differences between the studied couples as reported in Table 2.

Figure 3 reports the percentage of tyrosinase inhibition of the peel aqueous extracts (Akko and Wonderful) obtained by the innovative (a) and the traditional (b) extraction techniques. 


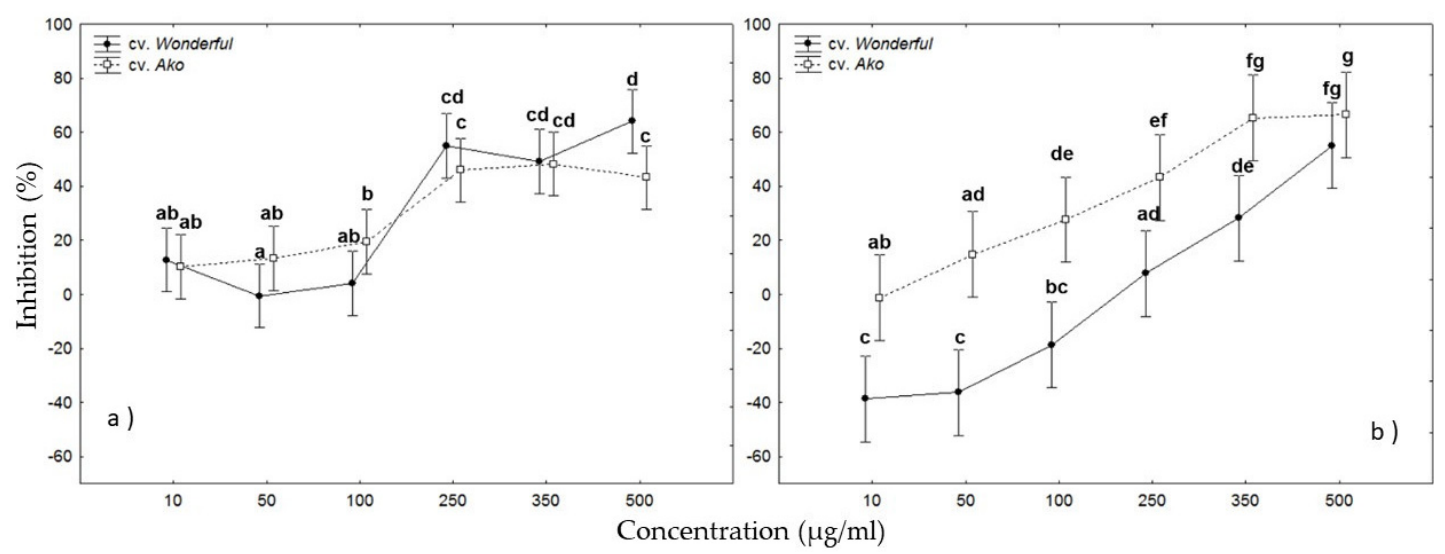

Figure 3. Percentage of tyrosinase inhibition of Akko and Wonderful pomegranate peel aqueous extracts obtained by innovative (a) and the traditional (b) extraction techniques. Bars show mean values and SE of the replicated data as a function of concentration. The letters represent homogeneous groups with $p>0.05$ (LSD Fisher post-hoc test). Same letters denote groups that are not statistically different.

The PUAE extracts of the two cultivars showed inhibition values not significantly different at the different concentrations tested, except for those observed at $500 \mu \mathrm{g} / \mathrm{mL}$. More relevant differences were found for traditional decoctions: in these extracts the Akko cultivar showed greater inhibitions at all concentrations except the highest one considered. From the inhibition values obtained from the various concentrations tested, it was possible to calculate the EC50. In general, the extracts obtained from the innovative extraction technique had better EC50 values (AK_PUAE = $117.73 \mu \mathrm{g} / \mathrm{mL}$; WO_PUAE = $159.04 \mu \mathrm{g} / \mathrm{mL}$ ) compared to traditional extracts (AK_D $=147.38 \mu \mathrm{g} / \mathrm{mL}$; WO_D $=365.91 \mu \mathrm{g} / \mathrm{mL}$ ).

In order to analyze the data using a multivariate approach, principal component analysis (PCA), an unsupervised pattern recognition technique, was applied to the data matrix $D_{8,8}$, whose rows are the extracts and the columns are all the determined experimental variables. In detail, the eight extracts are those obtained by PUAE and decoction for both cultivars, in duplicate, and correspondingly categorized. PCA was performed on the autoscaled data matrix, since autoscaling, which consists of mean-centering followed by division of each column (variable) by its standard deviation, allows elaboration of multivariate data characterized by different scales and units. Figure $4 a-b$ shows the PCA results obtained from the above-mentioned data matrix $D_{8,8}$. 

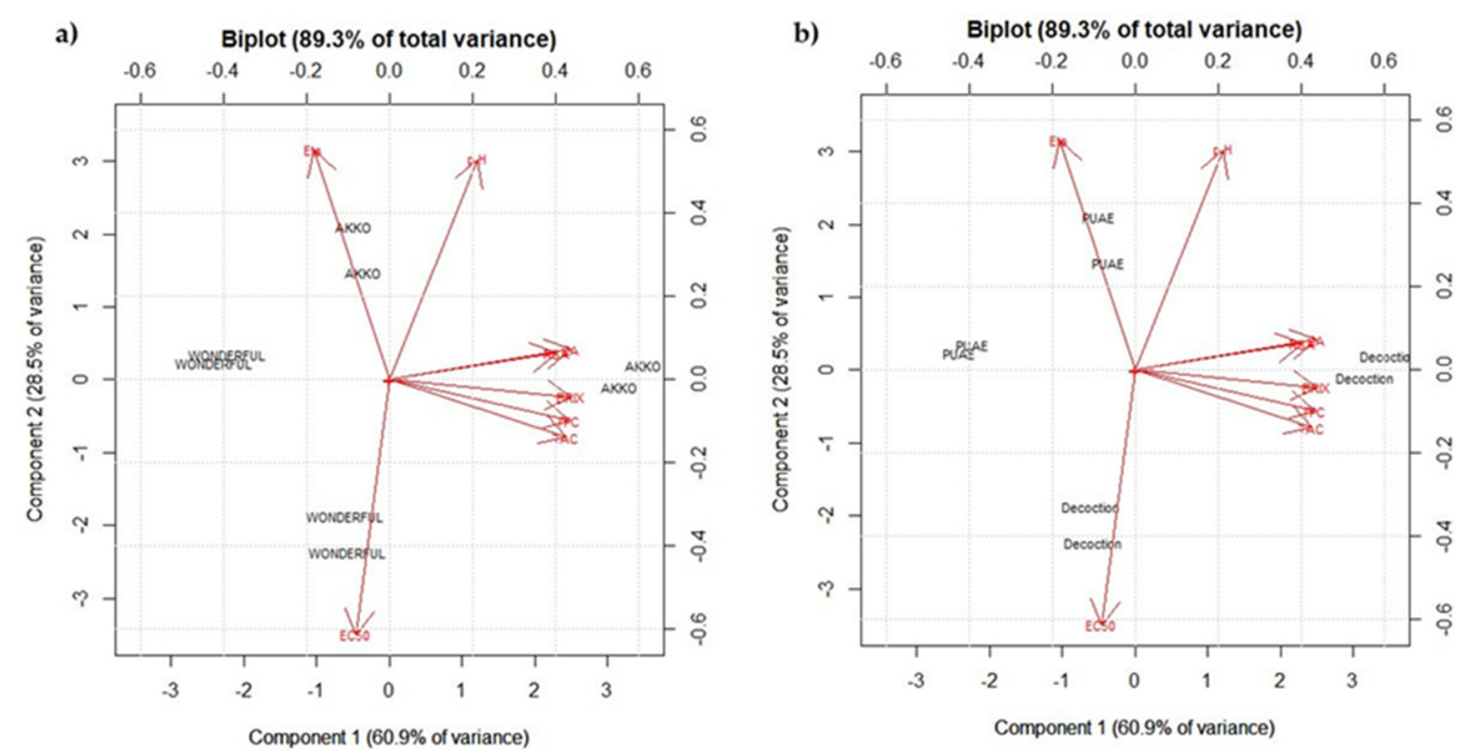

Figure 4. Biplot (score and loading plot) on PC1-PC2 obtained by principal component analysis (PCA). (a): extracts are categorized by the different cultivar (Akko and Wonderful); (b): data are categorized by the different extraction techniques (D and PUAE).

The first two principal components (PCs) together explain almost $90 \%$ of the total information of the whole data set since they visualize almost $90 \%$ of the total variance of the dataset. Figure $4 \mathrm{a}, \mathrm{b}$ shows the biplot PC1 vs. PC2, which represents the scores and loadings plot, on the first two PCs, highlighting the different categorization of the extracts ( $\mathrm{a}$ - the extracts are categorized by the different cultivar; and $b$ - the data are categorized by the different extraction techniques).

PC1, the direction of maximum variance $(60.9 \%)$, for both cultivars, discriminates the PUAE extracts from decoctions which have more positive scores on the first PC (Figure $4 b$ ). Decoction could be associated with higher ${ }^{\circ}$ Brix, RSA, TPC, TAC, and EA (highest loadings on PC1). Nevertheless, as far as anti-tyrosinase activity is concerned, PC2, whose variance is about $29 \%$, is the most important component, highlighting the indirect correlation between the ET content (highest loadings on PC2) and the EC50 (lowest loading on PC2). For both cultivars, PUAE extracts could be associated with the highest ET content (highest loading on PC2) and the highest anti-tyrosinase activity. AK_PUAE, which represents the extract with the highest content of ETs, is the one endowed with the highest anti-tyrosinase activity (lowest EC50). Since PCs are mathematically uncorrelated (orthogonal) variables, it seems that ET content, among all the determined variables, is the most important to determine the anti-tyrosinase activity, together with $\mathrm{pH}$, whose highest value in the Akko cultivar could further positively influence the anti-tyrosinase activity $[10,11]$. The remaining variables, having high loadings on the PC1, do not seem correlated with the anti-tyrosinase activity.

Water was employed as an extraction solvent with the dual aim of achieving a greener and safer chemistry approach compared to methanol or other organic solvents, and developing a low-cost recovery strategy of these by-products. The aqueous decoction of pomegranate peels represents the simplest and cheapest strategy to rapidly obtain extracts, and has widely been used as a folk remedy in traditional medicine. In fact, due to its high concentration of tannins, which gives the peel a strong astringency, the peel decoction has been used to treat dysentery and other gastro-intestinal disorders [45]. Moreover, another advantage of decoction is that, being an extemporaneous preparation, there is no need to stabilize the extract. This is particularly relevant in the case of the extract obtained with ultrasound, since the stability over time of aqueous extracts is very limited.

Ultrasound-assisted extraction (UAE) is a green and energy-saving technology which is being increasingly employed in the extraction of natural products as a simple and efficient alternative to conventional extraction techniques. Substantial shortening of extraction time, reduction of reagent consumption, increase of extraction yield, and faster kinetics are the most important advantages of 
UAE [4-26]. The sonication used in pulsed mode (PUAE) drastically reduces the operating temperature, allowing the extraction of thermolabile compounds. The superiority of PUAE to produce antioxidants from pomegranate peels has been previously demonstrated [46]. Longer times of extraction have not been tested in the present paper in order to minimize the potential degradation of the aqueous extracts. In fact, during the sonication process of vegetal material in water, a small amount of active oxidizing species (i.e., HO- and hydrogen atoms) are generated, and this process is time-dependent [47]. Although these aqueous extracts may require a further formulation step for preservation over time [48], we did not tackle this point, since our priority was to emphasize whether or not they deserve further formulative investigations.

\section{Conclusions}

The results of this research highlighted that water, as an extraction solvent, was able to extract, in a limited extraction time (10 $\mathrm{min})$, significant amounts of bioactive compounds, particularly ETs, from pomegranate peels of the commercial cultivars most widespread in Italy: Akko and Wonderful. This is of great importance considering the need for 'greener' and safer extractions of natural compounds.

Compared to PUAE, traditional decoction has the advantages of being easily and extemporaneously obtainable and leads to extracts endowed with higher values of EA, TPC, RSA, and TAC for both the cultivars investigated. Nevertheless, PUAE has the advantage of yielding extracts endowed with a higher content of ETs, whose content is directly correlated with enzymatic activity.

Based on the results obtained, both of the 'green' extraction strategies proposed proved to be promising methods to produce low-cost anti-tyrosinase ingredients. EA is already approved as a lightening/whitening agent in cosmetic formulations; however, considering these results, the cheaper natural extract rich in ETs could represent a potential new cosmetic ingredient. Stabilization to preserve the polyphenolic compounds over time and formulation of a hydrophilic gel containing the pomegranate peel extract, as well as the tests necessary to evaluate their in vivo lightening properties, are currently under study.

These findings represent an important aim for pomegranate juice manufacturers, since peels are the major form of processing waste, and their disposal is expensive and not eco-friendly.

Supplementary Materials: The following are available online at http://www.mdpi.com/2076-3417/10/8/2795/s1, Figure S1: HPLC separation of EA in one pomegranate peel aqueous extract, Figure S2: HPLC chromatogram with anthocyanin profile of one pomegranate peel aqueous extract.

Author Contributions: Conceptualization, R.B. and P.Z.; methodology, R.B., F.T., P.G., P.M.; software, F.T., R.B., P.G.; investigation, F.T., P.M., S.C.; writing — original draft preparation, R.B., F.T.; writing—-review and editing, R.B., P.G.; supervision, R.B., P.Z., P.G. All authors have read and agreed to the published version of the manuscript.

Funding: This work was partially funded by Duferco Engineering SPA.

Acknowledgments: The authors are grateful to LOME SuperFruit for providing the pomegranate samples.

Conflicts of Interest: The authors declare no conflict of interest.

\section{References}

1. Chandra, R.; Babu, D.K.; Jadhav, V.T.; Teixeira da Silva, J.A. Origin, history and domestication of pomegranate. Fruit Veg. Cereal Sci. Biotechnol. 2010, 4, 1-6.

2. Zarfeshany, A.; Asgary, S.; Javanmard, S. Potent health effects of pomegranate. Adv. Biomed. Res. 2014, 3, 100. [CrossRef] [PubMed]

3. Teixeira da Silva, J.A.; Rana, T.S.; Narzary, D.; Verma, N.; Meshram, D.T.; Ranade, S.A. Pomegranate biology and biotechnology: A review. Sci. Hortic. 2013, 160, 85-107. [CrossRef]

4. Turrini, F.; Zunin, P.; Catena, S.; Villa, C.; Alfei, S.; Boggia, R. Traditional or hydro-diffusion and gravity microwave coupled with ultrasound as green technologies for the valorization of pomegranate external peels. Food Bioprod. Process. 2019, 117, 30-37. [CrossRef]

5. Bar-Ya'akov, I.; Tian, L.; Amir, R.; Holland, D. Primary Metabolites, Anthocyanins, and Hydrolyzable Tannins in the Pomegranate Fruit. Front. Plant Sci. 2019, 10, 620. [CrossRef] 
6. Akhtar, S.; Ismail, T.; Fraternale, D.; Sestili, P. Pomegranate peel and peel extracts: Chemistry and food features. Food Chem. 2015, 174, 417-425. [CrossRef]

7. Šavikin, K.; Živković, J.; Alimpić, A.; Zdunić, G.; Janković, T.; Duletić-Laušević, S.; Menković, N. Activity guided fractionation of pomegranate extract and its antioxidant, antidiabetic and antineurodegenerative properties. Ind. Crop. Prod. 2018, 113, 142-149. [CrossRef]

8. Alfei, S.; Turrini, F.; Catena, S.; Zunin, P.; Grilli, M.; Pittaluga, A.; Boggia, R. Ellagic Acid a multi-target bioactive compound for drug discovery in CNS? A narrative review. Eur. J. Med. Chem. 2019, 183, 111724. [CrossRef]

9. Tomás-Barberán, F.A.; González-Sarrías, A.; García-Villalba, R.; Núñez-Sánchez, M.A.; Selma, M.V.; García-Conesa, M.T.; Espín, J.C. Urolithins, the rescue of "old" metabolites to understand a "new" concept: Metabotypes as a nexus among phenolic metabolism, microbiota dysbiosis, and host health status. Mol. Nutr. Food Res. 2017, 61, 1500901. [CrossRef]

10. Fawole, O.A.; Makunga, N.P.; Opara, U.L. Antibacterial, antioxidant and tyrosinase-inhibition activities of pomegranate fruit peel methanolic extract. BMC Complement. Altern. Med. 2012, 12, 200. [CrossRef]

11. Mphahlele, R.R.; Fawole, O.A.; Makunga, N.P.; Opara, U.L. Effect of drying on the bioactive compounds, antioxidant, antibacterial and antityrosinase activities of pomegranate peel. BMC Complement. Altern. Med. 2016, 16, 143. [CrossRef] [PubMed]

12. Zolghadri, S.; Bahrami, A.; Hassan Khan, M.T.; Munoz-Munoz, J.; Garcia-Molina, F.; Garcia-Canovas, F.; Saboury, A.A. A comprehensive review on tyrosinase inhibitors. J. Enzym. Inhib. Med. Chem. 2019, 34, 279-309. [CrossRef] [PubMed]

13. Jablonski, N.G.; Chaplin, G. The colours of humanity: The evolution of pigmentation in the human lineage. Philos. Trans. R. Soc. B Biol. Sci. 2017, 372, 20160349. [CrossRef] [PubMed]

14. Ito, S.; Wakamatsu, K. Chemistry of melanins. In The Pigmentary System. Physiology and Pathophysiology, 2nd ed.; Nordlund, J.J., Boissy, R.E., Hearing, V.J., King, R.A., Ortonne, J.P., Eds.; Blackwell Publishing: Oxford, UK, 2006; pp. 282-310.

15. Lee, S.J.; Hann, S.K.; Im, S. Mixed Epidermal and Dermal Hypermelanoses and Hyperchromias. In The Pigmentary System. Physiology and Pathophysiology, 2nd ed.; Nordlund, J.J., Boissy, R.E., Hearing, V.J., King, R.A., Ortonne, J.P., Eds.; Blackwell Publishing: Oxford, UK, 2006; pp. 1020-1025.

16. Won, Y.K.; Loy, C.J.; Randhawa, M.; Southall, M.D. Clinical efficacy and safety of 4-hexyl-1,3-phenylenediol for improving skin hyperpigmentation. Arch. Dermatol. Res. 2014, 306, 455-465. [CrossRef] [PubMed]

17. Solano, F. On the Metal Cofactor in the Tyrosinase Family. Int. J. Mol. Sci. 2018, 19, 633. [CrossRef]

18. Mason, H.S.; Fowlks, W.L.; Peterson, E. Oxygen transfer and electron transport by the phenolase complex. J. Am. Chem. Soc. 1955, 107, 4015-4027. [CrossRef]

19. Cosmetic Ingredient Database. Available online: https://ec.europa.eu/growth/toolsdatabases/cosing/index. cfm?fuseaction=search.details_v2\&id=56131 (accessed on 22 January 2020).

20. Special Chem INCI Database Directory (International Nomenclature of Cosmetic Ingredients Database). Available online: https://cosmetics.specialchem.com/searchsites/searchproducts?q=ellagic\%20 (accessed on 22 January 2020).

21. Shimogaki, H.; Tanaka, Y.; Tamai, H.; Masuda, M. In vitro and in vivo evaluation of ellagic acid on melanogenesis inhibition. Int. J. Cosmet. Sci. 2000, 22, 291-303. [CrossRef]

22. Özer, Ö.; Mutlu, B.; Kıvçak, B. Antityrosinase Activity of Some Plant Extracts and Formulations Containing Ellagic Acid. Pharm. Biol. 2007, 45, 519-524. [CrossRef]

23. Turrini, F.; Boggia, R.; Donno, D.; Parodi, B.; Beccaro, G.; Baldassari, S.; Signorello, M.G.; Catena, S.; Alfei, S.; Zunin, P. From pomegranate marcs to a potential bioactive ingredient: A recycling proposal for pomegranate squeezed-marcs. Eur. Food Res. Technol. 2020, 246, 273-285. [CrossRef]

24. Rajha, H.N.; Abi-Khattar, A.M.; El Kantar, S.; Boussetta, N.; Lebovka, N.; Maroun, R.G.; Louka, N.; Vorobien, E. Comparison of aqueous extraction efficiency and biological activities of polyphenols from pomegranate peels assisted by infrared, ultrasound, pulsed electric fields and high-voltage electrical discharges. Innov. Food Sci. Emerg. 2019, 58, 102212. [CrossRef]

25. Panda, D.; Manickam, S. Cavitation Technology-The Future of Greener Extraction Method: A Review on the Extraction of Natural Products and Process Intensification Mechanism and Perspectives. Appl. Sci. 2019, 9, 766. [CrossRef] 
26. Chemat, F.; Rombaut, N.; Sicaire, A.G.; Meullemiestre, A.; Fabiano-Tixier, A.S.; Abert-Vian, M. Ultrasound assisted extraction of food and natural products. Mechanisms, techniques, combinations, protocols and applications. A review. Ultrason. Sonochem. 2017, 34, 540-560. [CrossRef] [PubMed]

27. Passafiume, R.; Perrone, A.; Sortino, G.; Gianguzzi, G.; Saletta, F.; Gentile, C.; Farina, V. Chemical-Physical characteristics, polyphenolic content and total antioxidant activity of three Italian-grown pomegranate cultivars. NFS J. 2019, 16, 9-14. [CrossRef]

28. Singleton, V.L.; Rossi, J.A., Jr. Colorimetry of total phenolics with phosphomolybdic-phosphotungstic acid reagents. Am. J. Enol. Viticult. 1965, 16, 144-158.

29. Brand-Williams, W.; Cuvelier, M.E.; Berset, C. Use of a free radical method to evaluate antioxidant activity. LWT Food Sci. Technol. 1995, 28, 25-30. [CrossRef]

30. Huerga-González, V.; Lage-Yusty, M.A.; Lago-Crespo, M.; López-Hernández, J. Comparison of methods for the study of ellagic acid in pomegranate juice beverages. Food Anal. Method 2005, 8, 2286-2293. [CrossRef]

31. Turrini, F.; Boggia, R.; Leardi, R.; Borriello, M.; Zunin, P. Optimization of the Ultrasonic-Assisted Extraction of Phenolic Compounds from Oryza Sativa, L. 'Violet Nori' and Determination of the Antioxidant Properties of its Caryopses and Leaves. Molecules 2018, 23, 844. [CrossRef]

32. Barnes, R.J.; Dhanoa, M.S.; Lister, S.J. Standard normal variate transformation and de-trending of near-infrared diffuse reflectance spectra. Appl. Spectrosc. 1989, 43, 772-777. [CrossRef]

33. Italian Chemical Society. Division of Analytical Chemistry-Group of Chemometrics. CAT Chemometric Agile Tool. Available online: http://www.gruppochemiometria.it/index.php/software (accessed on 10 January 2020).

34. Višnjevec, A.M.; Ota, A.; Skrt, M.; Butinar, B.; Možina, S.S.; Cimerman, N.G.; Nečemer, M.; Arbeiter, A.B.; Hladnik, M.; Krapac, M.; et al. Genetic, Biochemical, Nutritional and Antimicrobial Characteristics of Pomegranate (Punica granatum L.) Grown in Istria. Food Technol. Biotechnol. 2017, 55, 151-163. [CrossRef]

35. Fawole, A.M.; Opara, U.L. Developmental changes in maturity indices of pomegranate fruit: A descriptive review. Sci. Hortic. 2013, 159, 152-161. [CrossRef]

36. Sójka, M.; Janowski, M.; Grzelak-Błaszczyk, K. Stability and transformations of raspberry (Rubus idaeus L.) ellagitannins in aqueous solutions. Eur. Food Res. Technol. 2019, 245, 1113-1122. [CrossRef]

37. Živković, J.; Šavikin, K.; Janković, T.; Ćujić, N.; Menković, N. Optimization of ultrasound-assisted extraction of polyphenolic compounds from pomegranate peel using response surface methodology. Sep. Purif. Technol. 2018, 194, 40-47. [CrossRef]

38. Zhao, X.; Yuan, Z.; Fang, Y.; Yin, Y.; Feng, L. Characterization and evaluation of major anthocyanins in pomegranate (Punica granatum L.) peel of different cultivars and their development phases. Eur. Food Res. Technol. 2013, 236, 109-117. [CrossRef]

39. Fischer, U.A.; Carle, R.; Kammerer, D.R. Identification and quantification of phenolic compounds from pomegranate (Punica granatum L.) peel, mesocarp, aril and differently produced juices by HPLC-DAD-ESI/MSn. Food Chem. 2011, 127, 807-821. [CrossRef] [PubMed]

40. Zhu, F.; Yuan, Z.; Zhao, X.; Yin, Y.; Feng, L. Composition and contents of anthocyanins in different pomegranate cultivars. Acta Hortic. 2015, 1089, 35-42. [CrossRef]

41. El-Said, M.M.; Haggag, H.F.; Fakhr El-Din, H.M.; Gad, A.S.; Farahat, A.M. Antioxidant Activities and Physical Properties of Stirred Yoghurt Fortified with Pomegranate Peel Extracts. Ann. Agric. Sci. 2014, 59, 207-212. [CrossRef]

42. Kaderides, K.; Papaoikonomou, L.; Serafim, M.; Goula, A.M. Microwave-assisted extraction of phenolics from pomegranate peels: Optimization, kinetics, and comparison with ultrasounds extraction. Chem. Eng. Process. Process Intensif. 2019, 137, 1-11. [CrossRef]

43. Çam, M.; Hışıl, Y. Pressurised water extraction of polyphenols from pomegranate peels. Food Chem. 2010, 123, 878-885. [CrossRef]

44. Kaderides, K.; Goula, A.M.; Adamopoulos, K.G. A process for turning pomegranate peels into a valuable food ingredient using ultrasound-assisted extraction and encapsulation. Innov. Food Sci. Emerg. 2015, 31, 204-215. [CrossRef]

45. Bhowmik, D.; Gopinath, H.; Kumar, B.P.; Duraivel, S.; Aravind, G.; Kumar, K.P.S. Medicinal Uses of Punica granatum and Its Health Benefits. J. Pharmacog. Phytochem. 2013, 1, $28-35$. 
46. Pan, Z.; Qu, W.; Ma, H.; Atungulu, G.G.; McHugh, T.H. Continuous and pulsed ultrasound-assisted extractions of antioxidants from pomegranate peel. Ultrason. Sonochem. 2011, 18, 1249-1257. [CrossRef] [PubMed]

47. Vinatoru, M.; Mason, T.J.; Calinescu, I. Ultrasonically assisted extraction (UAE) and microwave assisted extraction (MAE) of functional compounds from plant materials. Trend Anal. Chem. 2017, 97, 159-178. [CrossRef]

48. Panichayupakaranant, P.; Itsuriya, A.; Sirikatitham, A. Preparation method and stability of ellagic acid-rich pomegranate fruit peel extract. Pharm. Biol. 2010, 48, 201-205. [CrossRef] [PubMed]

(C) 2020 by the authors. Licensee MDPI, Basel, Switzerland. This article is an open access article distributed under the terms and conditions of the Creative Commons Attribution (CC BY) license (http://creativecommons.org/licenses/by/4.0/). 